\title{
Rethinking the gold standard for correction of paravalvular leak
}

\author{
Mathew R. Williams, MD, Michael S. Koeckert, MD, and Eugene A. Grossi, MD
}

\author{
From the Department of Cardiothoracic Surgery, New York University School of Medicine, New York, NY. \\ Disclosures: Authors have nothing to disclose with regard to commercial support. \\ Received for publication Dec 15, 2015; accepted for publication Dec 16, 2015; available ahead of print Jan 22, \\ 2016. \\ Address for reprints: Eugene A. Grossi, MD, Department of Cardiothoracic Surgery, NYU Medical Center, \\ Ste 9-V, 530 First Ave, New York, NY 10016 (E-mail: eugene.grossi@nyumc.org). \\ J Thorac Cardiovasc Surg 2016;151:1267-8 \\ $0022-5223 / \$ 36.00$ \\ Copyright (C) 2016 by The American Association for Thoracic Surgery \\ http://dx.doi.org/10.1016/j.jtcvs.2015.12.034
}

Clinically significant paravalvular leak (PVL) has been associated with mediocre long-term survival for both mitral and aortic prostheses. Until recently, surgical correction by repair or replacement has been the only option. Over the past decade, transcatheter reduction has grown in popularity but there are no large cohorts comparing the two, and a randomized comparison trial will likely never be pursued. In the absence of a comparative trial, we must consider all available data, despite the heterogeneity and largely retrospective nature, to guide our clinical decision making.

In this issue of the Journal, the report by Bouhout and colleagues $^{1}$ presents a thorough analysis of the largest surgical cohort with the longest follow-up to date. Of their 190 patients, 120 had PVL in the mitral position, 63 in the aortic position, and 7 patients had both. Interestingly, $89 \%$ of their cohort had mechanical prostheses. The isolated mitral and aortic groups had similar rates of PVL repair, $76 \%$ and $70 \%$, respectively, as opposed to re-replacement. Thirty-day mortality was $7 \%$ overall, with mitral PVL patients doing worse than the isolated aortic PVL patients ( $8 \%$ vs $3 \%$, respectively). With median follow-up of 5 years, PVL recurrence was not insignificant: $3 \%$ at 1 year, $14 \%$ at 5 years, and $32 \%$ by 10 years - an annualized rate of $4 \%$ per year. Five-year survival was $73 \%$. The authors conclude that the results following surgical correction of PVL are "acceptable," whereas the "hazard of recurrence remains high." 1 Interestingly, their discussion obliquely touches upon their changing patient substrate. They state, "A recently published meta-analysis (of transcatheter PVL reduction) has shown that this procedure has the potential for relative improvement in cardiac mortality and symptoms when successful. Whereas surgical treatment of PVL remains the gold standard, more comparative studies are needed to assess which patients could benefit from transcatheter PVL correction."

What is not contained in the surgical experience from Quebec is their significant institutional experience with transcatheter PVL reduction that was published previously. In the world's second-largest report on transcatheter PVL

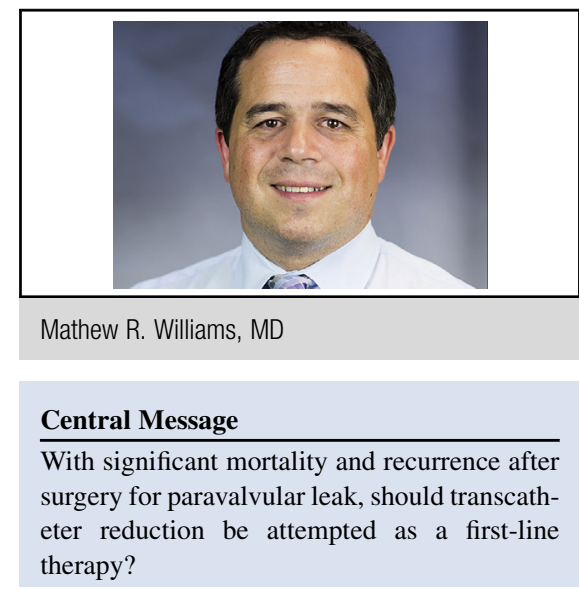

See Article page 1260 .

closure, Nobel and colleagues ${ }^{2}$ presented long-term outcomes of 56 patients (12 aortic and 44 mitral) with a $75 \%$ procedural success rate and a 30-day mortality of $8.9 \%$ for all comers. In the 42 patients with initial success there was a 4.8\% 30-day mortality. Roughly, the 3-year survival for successful patients was $50 \%$. Despite the initial success, 7 of these 42 would require repeat valve surgery: 2 within a month, 2 more within a year, and the remaining 3 by 3 years. Fourteen patients had initial failure with $6(43 \%)$ undergoing surgery subsequently. There was a high mortality associated with failure (3 out of $14 ; 21 \%$ ).

The only publication reviewing both surgical and transcatheter repair of PVL was from Milan in which Taramasso and colleagues ${ }^{3}$ reported on 139 patients undergoing PVL reduction. Through a "multimodality decision-making process" they chose an individualized approach with 17 patients undergoing transcatheter closure and the remaining 122 undergoing surgery. Although the number of transcatheter patients was highly selective, procedural success was achieved in $94 \%$ of patients (16 out of 17) with no 30-day mortality. The surgical group had an in-hospital mortality of $9.3 \%$. The largest transcatheter cohort comes from the Mayo clinic, ${ }^{4}$ where 126 patients underwent this procedure. Successful PVL correction was achieved in $75 \%$, with $15.9 \%$ requiring subsequent surgery; 30-day mortality was $2.4 \%$.

Reviewing the Quebec experience, it is apparent that their current profile of surgical PVL patients are those who have had an evaluation or attempt for transcatheter closure by very experienced operators. Likewise, in this current era of more sophisticated imaging modalities 
alongside more advanced transcatheter techniques and devices, our institutional bias is that transcatheter correction be attempted in most cases before proceeding to surgery. Whereas long-term survival after either surgery or successful transcatheter repair has been consistently mediocre, the current data suggest at least comparable if not better short-term results following successful transcatheter repair, and recent studies show a low rate of periprocedural complications in those that fail. The data suggest that there is a $75 \%$ chance of success with little downside in attempting transcatheter correction as a first-line approach for these patients.

Heart valve teams need the experience to evaluate transcatheter therapy for a given PVL, and the capability to provide it where appropriate as a first-line therapy.

\section{References}

1. Bouhout I, Mazine A, Ghoneim A, Millàn X, El-Hamamsy I, Pellerin M, et al. Long-term results after surgical treatment of paravalvular leak in the aortic and mitral position. J Thorac Cardiovasc Surg. 2016;151:1260-6.e1.

2. Noble S, Jolicoeur EM, Basmadjian A, Levesque S, Nozza A, Potvin J, et al. Percutaneous paravalvular leak reduction: procedural and long-term clinical outcomes. Can J Cardiol. 2013;29:1422-8.

3. Taramasso M, Maisano F, Latib A, Denti P, Guidotti A, Sticchi A, et al. Conventional surgery and transcatheter closure via surgical transapical approach for paravalvular leak repair in high-risk patients: results from a single-centre experience. Eur Heart J Cardiovasc Imaging. 2014;15:1161-7.

4. Sorajja P, Cabalka AK, Hagler DJ, Rihal CS. Long-term follow-up of percutaneous repair of paravalvular prosthetic regurgitation. J Am Coll Cardiol. 2011;58:2218-24. 